\title{
A Linguistic Discursive Analysis of Techno-Colonialism Through the Post-cyberpunk Literature
}

\author{
Saba Zaidi ${ }^{1}$, Mehwish Sahibzada ${ }^{2}$, Saman Salah ${ }^{1}$, Anisa Tul Mehdi ${ }^{1} \&$ Durdana Rafique $^{1}$ \\ ${ }^{1}$ English Department, SBK Women's University, Quetta, Pakistan \\ ${ }^{2}$ English Department, Baluchistan University of Information Technology Engineering and Management \\ Sciences, Quetta, Pakistan \\ Correspondence: Mehwish Sahibzada, English Department, Baluchistan University of Information Technology \\ Engineering and Management Sciences, Quetta, Pakistan. E-mail: mehwishsahibzada@gmail.com
}

Received: June 15, 2018 Accepted: July 7, 2018 Online Published: July 29, 2018

doi:10.5539/ijel.v8n6p131 URL: https://doi.org/10.5539/ijel.v8n6p131

\begin{abstract}
Technological advancement has made the world a complex arena of day to day transforming phenomenon. In such a complex and technologically progressive world nothing is static instead things have become technology oriented. The socio-historical phenomena like orientalism and imperialism are also not free from technological progress. Similarly, literature of the contemporary times has become Postmodernist for it now aims to represent the current human experiences. The quality of the Postmodernist literature is to represent and dismantle the socio-cultural constructions that use to perpetuate control and power. The objective of this research is twofold; it has projected the world of technological progress and innovation through the analysis of the selected Post-cyberpunk novel Accelerando (2005) by Charles Stross, The Windup Girl (2009) by Paolo Bacigalupi and The Rapture of the Nerds (2012) by Cory Doctorow and Charles Stross. Socio-Cognitive analysis (van Dijk, 2008) has projected the linguistic discursive analysis of techno-colonialism in order to answer the research questions. The study has also introduced Post-cyberpunk as the genre of Postmodernist twenty-first century literature. The findings of the research have suggested that the selected Post-cyberpunk novels have not only represented techno-colonialism but they have also characterized the impact and influence of the techno-colonizers throughout the world.
\end{abstract}

Keywords: techno-colonialism, socio-cognitive, discursive, colonialism

\section{Introduction}

Since the time immemorial technology has been influencing the cultures and individuals as a motivational force. It would not be wrong to call this influence a clandestine colonial dynamism that has engulfed the global village to its cure. From day to day domestic activities to formal make overs and highly advance levels, technology is playing a vital role to transform the different existing phenomena. Even the things that use to have static identities such as biologically form entities have also lost their signifiers in the area of information technology. The advancement in information technology has created a 'virtual' or 'hyper' reality with abundant replications and depictions that has left the concept of identity much more debatable than it was before. It has become hard to trace the real identity of any object, concept and entity for there exist multiple representations of a single entity. In such a complex scenario nothing is permanent; instead concepts and phenomena have become obsolete.

It has been a tendency of literature to represent the society and culture in which it is produced. The Contemporary literature just like its counter-part (linguistics) has become technology oriented. Terms like orientalism, globalization, capitalism and colonization etc. are also affected by the technological progress and the prefix 'techno' has been added before all such terms and socio-cultural phenomenon, globally. Post-cyberpunk literature is one such subgenre of science fiction literature that has surpassed the tag of pulp literature and entered into the realm of Postmodernist literature due to the fact that Post-cyberpunk novels deal with the computer technology. The plots of these narratives are based on socio-cultural themes such as the individuals and their struggles against multinational corporations, capitalism and colonization. Apart from these aspects Post-cyberpunk literature represents the subversion of socially and biologically constructed identities such as gender, class, religion and age. Nonetheless it also deconstructs the existing power structures and challenges the hegemony based systems. 
This study carries out a discursive analysis of selected Post-cyberpunk novels: The Windup Girl (2009) by Paolo Bacigalupi, Accelerando (2005) by Charles Stross and The Rapture of the Nerds (2012) by Cory Doctorow and Charles Stross. Critical Discourse Analysis has focused the eminence of Post-cyberpunk as an emerging representative genre of Postmodernist twenty-first century literature (Zaidi, 2016). Sufficient critical work has been done in Post-cyberpunk this study is exclusive to the above mentioned novels.

\section{Method}

The analysis of the selected Post-cyberpunk novels: The Rapture of the Nerds (2012), The Windup Girl (2009) and Accelerando (2005) is based upon the conceptual framework of Socio-cognitive Approach by van Dijk (2008) that is used both as a method and theory in order to analyze the theme of techno-colonialism. This study utilized the discursive practices and themes as the tools of analysis. In the light of the below mentioned review of literature the following research questions are posed:

Q1. How techno-colonialism is projected in the selected Post-cyberpunk novels?

Q2. How strong is the grasp of techno-colonizers to supersede and suppress the world through technology?

\section{Significance of Research}

This research aims to explore the theme of techno-colonialism in the above mentioned selected Post-cyberpunk novels. It aims to develop a perspective that Post-cyberpunk literature is not merely hard Science Fiction or virtual reality. Rather it is genuine and contemporary because of the depiction of social and cultural aspects. This research is also significant as it has highlighted the technologically modified notion of colonialism through the discursive linguistic analysis applied from the method of Socio-cognitive approach (van Dijk, 2008).

\section{Literature Review}

According to critical discourse analyst it is a well-established notion of social cognition that the discursive practice is a means to create reality. Discursive practices are social devices that address the sociocultural process through which meaning is formed and assumed. Discourse analysis looks at how reality and truth are constructed, negotiated, sustained and defied in social practices.

The objective of this study is to analyze the subversion of meanings in the discourse of certain novels, which are instrumental in the transformation and creation of social phenomenon like techno-colonialism. According Leeuwen (2008) "As discourses are social cognitions, socially specific ways of knowing social practices, they can be, and are, used as resources for representing social practices in text” (p. 6).

This study is intends to examine the hidden language patterns present in the selected novels. Schaffner and Wenden (1999) has discussed that the central aim of discourse analysis is to analyze language and its function in a social context. Critical discourse analysis includes both 'micro' and 'macro' structures for it goes beyond mere linguistic structures of the text and includes the social conditions of the text production and reception (van Dijk, 2008). Van Dijk has defined context as something that pertains to circumstances, situation and environment (van Dijk, 2008, p. 4). Fairclough, Wodak and Mulderring (2011) see it as an analytical category that has a vast range of meaning and identifies particular representations of social life.

$\mathrm{CDA}$ is influential and instrumental in order to understand the contemporary social reality because of the crucial advancement in the social order of discursive practice and the relation of discourse with other practices. CDA deals with language, speech, discourse and social structure. Van Dijk (2009) has enumerated three dimensions of discourse: "the use of language, the communication of beliefs (cognition) and interaction in social situations" (p. 2).

Hence, for the analysis, understanding, interpretation and explanation of any social phenomenon discursive analysis from Socio-cognitive Approach is a fruitful research enterprise. Cognition is a required medium of mediation to form a link between socio-linguistic paradigms. Apart from cognition the context is also required as a base to relate language and social elements. The context model provides sufficient knowledge required for the deconstruction of discourse practices as text and talk do not occur in isolation. The Socio-cognitive Approach apart from being a mental understanding of the text also aids the analyst to link the context with the content to make the communication relevant (van Dijk, 2009).

Socio-cognitive Approach takes place at the micro and macro levels. The micro level includes syntactic formal structures and lexical choices, and the macro level constitutes social aspects while the semantics deals with both cognitive and linguistic aspect. Some elements of the Socio-cognitive Approach are: context, discursive practices, themes, implication, topics, presupposition, lexical, semantic and connotative meanings. 
Van Dijk's (2008) Socio-cognitive Approach is based on the concept that social structures and discourse structures are mediated through social and personal cognition. In the light of van Dijk's (2008) cognitive triangle (individual, society and cognition), discourse is a communicative event whether written or oral, cognition both personal and social pertains to beliefs, ideas, and emotions while the society is context bound that includes both the micro and macro structures. Micro structures are the textual linguistic elements through which the communicative event, situation or interaction is delineated. Macro structures, on the other hand are historical, social, political, and cultural communicative events that are present in any society. As this study is based upon the analysis of Post-cyberpunk literature so a brief review of Cyberpunk and Post-cyberpunk literature is given below.

'Cyberpunk' is a combination of two words 'cyber' and 'punk' and its roots are not thoroughly literary. The word cyber refers to science it means a pilot and is derived from 'Cybernetics', which was coined by Wiener in his book titled as Cybernetics, or Control and Communication in the Animal and the Machine (1947) (Elias, 2009). During 1980s 'Cyberpunk' became an extensively acknowledged term for the representation of a peculiar type of cultural fabrication established in media, music and fiction. It is a combination of techno and punk subcultures and it represents human experience in a post-industrial information oriented society. The sociological base of Cyberpunk could be traced in hackers, crackers and phreaks subculture affiliated with computers. Therefore, with regard to postmodern ethics Cyberpunk literature is a hybrid and interdisciplinary phenomenon. The term 'Cyberpunk' was coined by Bethke in a story named Cyberpunk (1983). In order to represent a specific group of writers that included, Gibson, Sterling, Rucker and Cadigan, Dozois popularized the term as a movement (Elias, 2009, pp. 13-23).

Cyberpunk literature emerged in the late 70 s and early 80 s and it portrayed the drug culture along with the advancement of computer hacking. As a complete movement Cyberpunk came into being in 1984 when Gibson for the first time introduced cyberpunk and cyberspace in Neuromancer. The novel Neuronmancer met popular and critical success and turned out to be the first Science Fiction narrative to receive three major Science Fiction awards, Hugo, Nebula and Phillip K Dick. Cyberpunks were the first generation for whom technology in the form of satellite dishes, digital watches, video games and cellular phones was not an alienated phenomenon as they were used to such kind of technology. Rather they were part of their daily reality matrix. Cyberpunks embrace both the technological dreams and nightmares, they stress on a need to generate means to utilize technology for human purposes before they turn into mere software, which could be erased from multinational showground. Due to its ability to subvert the grand narrative and represent a world of multinational capitalism Cyberpunk genre became an important genre Postmodernism (McCaffery, 1991, pp. 11-13).

However, in 1990 a new wave appeared in Cyberpunk genre due to the historical and technological developments that has also altered the themes. The transition in Science Fiction narratives from first period of hard Science Fiction to the second phase of 'Cyberpunk' subgenre eventually culminated into the third phase of Post-cyberpunk subgenre in 1998. This transition occurred due to the change of plot and characters as the plots of Post-cyberpunk became social and universal. According to Person (1999), it is not only a change in name but also a complete transformation of themes and historical background (p. 5). Person in 1998, coined the term 'Post-cyberpunk' in order to distinguish Cyberpunk culture and fiction of 80 s from that of 90 s and beyond. He introduced the term 'Post-cyberpunk' in an article, Notes Toward a Post-cyberpunk Manifesto (1999) published in a Science Fiction magazine. If the early Cyberpunk novels such as Neuronmancer were written on the typewriters and delineated a future of virtual reality and cyberspace that has not yet come, the Post-cyberpunk novels have in fact materialized all these concepts. If the early Cyberpunk novels were based on technology in the Post-cyberpunk novels, the society is in fact technology. He differentiated the characteristics of Cyberpunk and Post-cyberpunk heroes. He argues that cyberpunk hero is cold, alienated and detached. The Post-cyberpunk heroes are from middle class, they have families and are integral members of the society.

The Post-cyberpunk has marked a shift towards social Science Fiction (Sterling, 1986, p. vii). Jameson (1991) says that Cyberpunk is "fully as much an expression of transnational corporate realities as it is of global paranoia itself" (p. 38). Post-cyberpunk with regard to this definition can be regarded as a maturing of this paranoia (Jorgensen, 2013, p. 241). Person (1999) argued that Bruce Sterling's Islands in Net (1988) should be termed as a Post-cyberpunk narrative as due to this novel Cyberpunk has reached a new maturation in the form of Post-cyberpunk. However, Snow Crash (1991) by Stephenson was the first novel to be branded as Post-cyberpunk because it has the complete Post-cyberpunk qualities as mentioned above.

Dirk H. R et al. (1996) have asserted that "The recent developments of server-based technology have seen the Internet become more and more pervasive ... 'Traditional' colonialism has always seen a physical on-the-ground presence of a colonial power" (pp. 1-2) but techno-colonialism has its grip on the world through technology. Jandric and Kuzmanic (2015) have projected the theoretical and practical opportunities for describing human 
expansion into the digital worlds. They further assert that "Technology and colonialism are dialectically intertwined - one cannot be thought of without the other" (p. 35). Said (1993) has stressed in Culture and Imperialism that geography is the very heart and soul of imperialism. Thus, technology as being an influential part of geography has become a tool of colonialism. It is now through the realm of technology that the colonizer is ruling or trying to rule the rest of the world.

Holtmeier (2009) suggests that "the proliferation of technology combined with a synthesis between the artificial and the organic in Ballard's novel, Crash, creates an unpredictable environment where the epiphenomenon is no longer phenomenal" (p. 2). Arnold (2005) on the other hand analyzed the literature on the history of technology as it relates to colonialism, decolonization and development in the extra-European world during the twentieth century. He has stressed on the point that in the modern times the mode of colonization has been transformed from colonialism to techno-colonialism. Seth (2009) has projected the fact that the 'civilization mission' of the west has taken the rout of technology.

The above comprehensive analysis of the related literature has brought forth the existing gap that the selected novels are not analyzed through the conceptual framework techno-colonialism.

\section{Analysis}

The following section is based upon the discursive linguistic analysis of the selected Post-cyberpunk novels. The novels The Rapture of the Nerds (2012), The Windup Girl (2009) and Accelerando (2005) are selected for analysis because they are the representative narratives of the genre Post-cyberpunk. As mentioned above this study is a discursive linguistic analysis of the themes therefore, the selected novels have the quality to characterize and project the themes in order to look into the discursivity of their discourses. These narratives are the stories of the struggles of different individuals who are instrumental in the representation of a technology oriented world where none of the phenomena are free from the grasp of technological progress.

In Accelerando the theme of technological development is highlighted through numerous characters and incidents that have developed the notion of techno-colonialism. The discussion between Sirhan and Pamela delineated that the excess of technological advancement may lead to destruction of sublime phenomena like humanity and relationships. Pamela has specifically referred to the period of pre-singularity when "humans were real humans, work was real work, and corporations were just things that did as we told them" (p. 270).

In the last part of the novel that is more philosophical than technological through the old version of Pamela the mega narrative of technological development that has led to techno-colonialism is put to prove. The subversion of world's economy is one of the basic traits of the novel that has projected the idea that due to technological progress the techno-colonizers will rule upon the world through technology to the extent that the economy of the entire world will fail to sustain. Eventually, the world will fall a victim in the hands of such elite techno-colonizers.

Accelerando frequently represents the capitalism and multinational consumers cultural, "Manfred has a suite at the Hotel Jan Luyken paid for by a grateful multinational consumer protection group, and an unlimited public transport pass paid for by a Scottish sambapunk band in return for services rendered" (p. 7). The commodification of necessities is discursively represented as such "Some commodities are expensive: The price of crude oil has been eighty euros a barrel and is edging inexorably up. Other commodities are cheap: computers, for example" (p. 89).

One of the noteworthy discursive aspects of the novel is the deconstruction of the humans through posthumans. The 'posthumanity' depicted in the novel suggests a novel kind of colonization. This colonization is technology oriented and 'posthumanity' or 'posthumans' are the neo-colonizers or the techno-colonizers who has taken hold of the entire world through technology. Consequently, the present form of physical humans will be totally vanished the twenty-third century. It is through Sirhan that the phenomenon of 'posthumanity' is classified, “... we are, by disposition, a conservative species, because in a static ecosystem that provides the best return on sunk reproductive investment costs. Yes, we change over time-we're more flexible than any other animal species to arise on Earth - but we're like granite statues compared to organisms adapted to life under Economics 2.0" (p. 307). Equivalent to the projection of posthumanity is the deconstruction of humanity as suggested by Manfred "...humans will be obsolete as economic units within a couple more decades" (p. 61). The discourse further narrates that by the sixth decade and third millennium the human species will be completely outdated. "...the damn fool human species has finally succeeded in making itself obsolete" (p. 241).

Pamela has highlighted the decomposition of humans, metahumans or augmented humans by the Vile Offspring through the discursive practice of ethnic cleansing. "Ethnic cleansing.... You take people who you define as 
being of little worth, first you herd them into a crowded ghetto with limited resources, then you decide those resources aren't worth spending on them, and the bullets are cheaper than bread" (p. 308). She has termed these Vile Offspring as 'Mind children' the very product of technological development and mind upload trends of humanity's own begotten offspring that one day will parish humans considering them to be worthless. Thus, these Vile Offspring are the agents of techno-colonization that will engulf the humanity through the excess of technological progress. The theme of techno-colonialism further gets momentum when Aineko the AI cat is represented as toying with the life of Manfred and Pamela. The cat has the power and control upon the lives of Manfred and Pamela that is representative of colonial hegemony. Srihan has projected the cat's superhuman powers as "What I mean is, Aineko is a human-equivalent, or better, artificial intelligence. Why do you think she keeps a cat's body?'... 'Because humans always underestimate anything that's small, furry and cute ..." (p. 313).

Amber Macx, Pamela and Manfred's daughter is also associated with theme of techno-colonialism. She enters into the scene in the second half of the text. Her character represents the peak of technological progress as she is a posthuman (techno-colonizer) who has taken hold of the other galaxies and planets when the resources of the planet earth are drained off. She is sole Queen of Ring Imperium a small planet in the orbit of Jupiter where she rules as a sovereign after she has deserted earth. Thus, it suggests that she has colonized the other planets in order to use and plunder the available resources of Jupiter. "She is the queen-the first individual to get her hands on so much mass and energy that she could pull ahead of the curve of binding technology, and the first to set up her own jurisdiction.... She has force majeure - even the Pentagon's infowarriors respect the Ring Imperium's autonomy for now" (p. 155).

Sirhan-al-Khurasani son of Amber and Sadeq is also a posthuman (techno-colonizer) who has taken hold of the planet Saturn as the ruler after the annihilation of Jupiter and Ring Imperium. He is a leader of a small zone in Saturn where he welcomes the copies or simulations of his parents and the other virtual crew, which represents dimension of his identity as a colonizer. "My name is Sirhan-al-Khurasani, and I am the prime contractor in charge of this small corner of the temporary Saturn terraforming project" (p. 303). Hence, from the above discussion it is clear that Accelerando has amply characterized the theme of techno-colonialism through various characters and passages.

The Rapture of the Nerds (2012) following the tradition of Accelerando illustrates similar patterns to represent the technological advancement that has given vent to techno-colonialism. The delineation of technology in the novel is initiated from the phrase 'disruptive technologies' which speaks of a technology that is unruly rowdy, and boisterous for the humanity just like colonialism. The individuals rather hominids like Huw dislike such technological flow that has made natural life obsolete and cumbersome that is why he is called a technophobe. Such an overexcited and disruptive technology has blended and intensified the entire cultures and economies of the world where permanency and validation has become the tales of the past and things have impermanent and transient social values. One such rowdy form of colonial technology intervening in the human life are the social medias like Facebook and Twitter that have made it hard to maintain privacy of individual lives and has made individual life commercial. The flow of social media like Facebook and Twitter are the elements of techno-colonialization that has taken the individuals of the entire world into their grip. Instead of being the cosmopolites or the citizens of world the individuals have become subjugates and slaves of Facebook, Twitter and other such dominating social media. As people prefer to spend more time in the virtual reality than the material reality, which according to them is more compliant than the material reality.

Facebook as a contrivance of information technology is projected in the passage where Huw and Bonnie reached the Charleston Ground Control in Carolina. They were received by computerized voice that has addressed them with Bonnie's Facebook account as her identity instead of their material identification on board, whereas the very next moment they were attacked by missiles. "Facebook-Goldman-AOL welcomes you to the United States of America. You have 14,023 new friend requests, which you will receive after this message from our sponsors. There are 5,348, 011 updates to the private policy for your review"' (Doctorow \& Stross, p. 103). Huw thought about the Facebook tales popular in Wales to scare naughty children that narrates the awful deeds done by the Facebook to its users after singularity.

The Rapture of the Nerds has some exclusive discursive practices that deconstruct the historical and social aspects like that of the famous treaties the Euro Americans made with the Native Americans to colonize them. The novel represents that from Libya to USA the entire world is ruled by the techno-colonizers and their agents. In the name of progress and civilization the techno-colonizers following the lead of their ancestors (Spanish and British colonizers) have taken hold of the entire world that has almost changed the ontology of being a human. The passaged where South Carolina (USA) is shown to be ruled by the cyborg ants known as the Hypercolony 
that has consumed most of the resources of the land leaving the hominids with singularity and the cloud speaks of techno-colonization:

Welcome to the American future, at the dusk of the twenty-first century.

Over the years and decades since the singularity, the ant colony has taken the entire Atlantic coast of the United States, has marched on Georgia and west to the Mississippi. It is an anarchist colony, whose females lay eggs without regard for the Queen .... (p. 112)

In the above passage America is portrayed as an anarchist state with no rules and rights the country boasts of instead the country is not even strong enough to protect the land from the infringement of the Hypercolony (techno-colonizers). The Hypercolony is a metaphor for colonization and the cyborg ants are the techno-colonizers who have taken the world into its grip. Every form of life present on the American land is eaten up by the ants leaving the Americans with only a trillion tons of processed food. The only way for them to survive is to build airtight seals around their homes and workplaces while they and their children wear spacesuits when they go out of their shelters.

Huw has called them the 'Other' who has invaded and taken hold of the entire land typically like a colonizer and consumed the entire resources. "There is an Other here, loose on the continent, capable of bringing low all that his kind has built" (p. 119). Techno-colonization is furthermore decentered in the last part of the discourse when the chair of the posthuman Planning Committee suggested that the Authority an AI entity is the Other who has motives to invade the earth. "'This isn't anything descended from the meatpeople that we were or uplifted. It's Other, capital O, and when you meet it, you won't have any doubt"' (pp. 279-280). The subversion of techno-colonization is also evident from another scene where Huw suggested that the policy of the alien entities is to divide and rule a characteristic technique of the colonizer. "Because they have divided the universe into two kinds of civilizations: allies and potential threats. Anything that looks like the latter, will, zap" " (p. 302).

The Windup Girl (2009) just like the above analyzed novels embodies the discursive aspects of technology that has expanded as bio-technology then it contracted to suffer the consequences of bioterrorism due to which contagious diseases and plagues are rampant that has made human life challenging. The novel represents a society that is in competition with nature, genetically modified food, genetically engineered animals and humans, and self-created plagues and diseases all these elements represent the flaws of excessive technological progress.

The character of Emiko (technologically produced cyborg) serves to be the symbol of techno-colonization. Individuals like Emiko have the potential to take over humanity and rule upon the technologically devastated world. It is a kind of world where humans fail to exits only the windups like Emiko can survive in the polluted world. Throughout the novel the windups are called as the New People that connotes the transforming vision about humanity. They represents an epistemological shift from old people to new people who are more refined, cultured and strong to resist the climatic and environmental changes. Thus, they are the neo-colonist who are more civilized than the old people that has created the hegemony of the windups. The importance of windups is further enhanced in the epilogue when Gibbons meets Emiko after the mass destruction of Thailand he tells her that she is better than humans in many respects. "Still, you are better than human in almost all other ways. Faster, smarter, better eyesight, better hearing. You are obedient, but you don't catch diseases like mine.' He waves at his scarred and oozing legs. 'You're lucky enough"' (p. 385). Gibbons is hopeful for a new world that will be inhabited by the New People the techno-colonizers. "Someday, perhaps, all people will be New People and you will look back on us as we look back at the poor Neanderthals" (p. 385).

The opening lines of the novel represents the idea of exotic Asia with the representation of a white man Anderson Lake standing in the Thai markets exploring the organic fruits and vegetables that are blister rust free and are a bounty for the orientalists to explore. The discourse also reveals symbols of cultural imperialism such as the trade company Carlyle \& Sons and Sir Francis Drake pub. The intended exploitation of Thai seedbanks by the American/European imperialists exemplifies the bio-colonizer's invasion and incursion of the exotic Asia that is the most crucial aspect of techno-colonization. Therefore, under the cover of SpringLife factory Anderson Lake an imperialist endeavors to discover the Thai seedbanks a valid source of calories to rule upon the world once again.

Imperialism is not a novel aspect of human society rather it is a centuries old tradition of the orientalist to invade the orient for the sake of plundering their land and resources. The passage related to Akkarat and Anderson characterizes imperialism since the time when the first group of missionaries invaded the Asian peninsula for the reason to convert them to Christianity. The below mentioned lines simultaneously decenter techno-colonization and the colonizers' intruding policies: 
'Ever since your missionaries landed on our shores, you have always sought to destroy us. During the old Expansion your kind tried to take every part of us. Chopping off the arms and legs of our country. It was only through our kings' wisdom and leadership that we avoided your worst. And yet still you weren't done with us. With the Contraction, your worshipped global economy left us starving and over-specialized.' (pp. 166-167).

The novel sufficiently depicts the tactics and the policies of the techno-orientalist in order to rule upon the world it nonetheless projects the influence of imperial power to control the Thai government ministries and mold the decisions accordingly. One such appropriate example is from the scene when after the civil unrest in Thailand Akkarat enters into an agreement with AgriGen representative Anderson according to which the seedbanks would become accessible to AgriGen. "Akkarat might have influence here, but AgriGen is everywhere else"” (p. 348). The last part of the text when Kanya was bound by Akkarat to take Elizabeth Boudry the new AgriGen representative to the seedbanks exquisitely represents techno-imperialism along with its power and control:

In the end, after all the blood and sweat and deaths and toil, after the struggles of seed saints and martyrs like Phra Seub, after the sale of girls like Kip to Gi Bu Sen and all the rest, it comes down to this. Farang standing triumphant at the heart of a kingdom betrayed once again by ministers uncaring for the crown. (p. 377)

The novel represents a world where calories are treasured more than money. Thailand is the only country left with this bounty but the corrupt officials and reliance upon the foreign investors with their kink-spring technology culminated into techno-imperialism consequently a root cause of techno-colonialism. Thus, The Windup Girl like rest of the above analyzed novels is a narrative that simultaneously represents and dismantles techno-colonialism as a power discourse. It projects a sense of disillusionment with the standard prescribed roles and statuses. At the same time it portrays dislike for hierarchy based divisions of human societies and hegemony of one group or class over the other.

\section{Conclusion}

This study has explored the representation of techno-colonialism and analyzed it through the various discursive linguistic practices within selected Post-cyberpunk novels. The analysis of techno-colonialism has projected that the grasp of techno-colonizers in order to suppress and surpass the world through technological progress is very strong and potent. Therefore, none of the countries of the world are free from the grip of technological modification and advancement. Such kind of technological output has made the entire world an arena of techno-colonization where neither individuals are free citizens of the world nor the societies are free from the technological encroachment. In order to seek answers for the research questions and to prove the objectives the researchers conducted an analysis based on the discursive practices and themes as techniques of Socio-Cognitive Approach (van Dijk, 2008). As it is the aim of literature to represent the society, similarly Post-cyberpunk literature exemplifies the contemporary issue of techno-colonialism.

\section{References}

Arnold, D. (2005). Europe, technology, and colonialism in the $20^{\text {th }}$ century. History and Technology, 21(1), 85-106. https://doi.org/10.1080/07341510500037537

Bacigalupi, P. (2009). The Windup Girl. New York: Night Shade Books.

Dirk. H. R. et al. (1996). The Electronic Colonization of the Pacific. Computer Mediated Communications Magazine, 3(2), 1-9. Retrieved from http:/www.december.com/cmc/mag/1996/feb/spen.html

Doctorow, C., \& Stross, C. (2012). The Rapture of the Nerds. New York: Tom Doherty Associates, LLC.

Elias, H. (2009). Cyberpunk 2.0: Fiction and Contemporary. Portugal: LabCom Books.

Fairclough, N., Muldering, J., \& Wodak R. (2011). Critical Discourse Analysis. In van Dijk (Ed.), Discourse Studies A Multidisciplinary Introduction (pp. 357-378). London: Sage Publishers. https://doi.org/10.4135/9781446289068.n17

Holtmeier, M. (2009). Scars, Cars, and Bodies without Organs: Techno-colonialism in J. G. Ballard's Crash. Leonardo Electronic Almanac, 16, 4-5. Retrieved from http:// scholar.google.com/citations?user

Jameson, F. (1991). Postmodernism, or, the Cultural Logic of Late Capitilism. Durham: Duke University Press.

Jandric, P., \& Kuzmanic, A. (2015). Digital Postcolonialism. IADIS International Journal, 13(2), 34-51.

Leeuwen, T. V. (2008). Discourse and Practice: New Tools for Critical Discourse Analysis. New York: Oxford University Press. https://doi.org/10.1093/acprof:oso/9780195323306.001.0001 
McCaffery, L. (Ed.). (1991). Storming the Reality Studio: A Casebook of Cyberpunk and Postmodern Science Fiction. Durham: Duke UP.

Person, L. (1999). Notes Toward a Postcyberpunk Manifesto. Slashdot.org. Retrieved from http://slashdot.org/features.html

Said, E. W. (1993). Culture and imperialism. New York: Vintage Books.

Schaffner, C., \& Wendin, A. (Eds.). (1999). Language and Peace. Amsterdam: Harwood Academic.

Seth, S. (2009). Putting knowledge in its place: science, colonialism, and the postcolonial. Postcolonial Studies, 12(4), 373-388. https://doi.org/10.1080/13688790903350633

Sterling, B. (1986). Mirrorshades: The Cyberpunk Anthology. New York: Arbor House.

Stross, C. (2005). Accelerando. New York: ACE Books.

Van, D. (2008). Discourse and Context: A Sociocognitive Approach. New York: Cambridge University Press.

Van, D. (2009). Society and Discourse: How Social Contexts Influence Text and Talk. New York: Cambridge University Press.

Zaidi, S. (2016). Post-cyberpunk Fiction: Issues of Identity and Representation. NUML, Islamabad.

\section{Copyrights}

Copyright for this article is retained by the author, with first publication rights granted to the journal.

This is an open-access article distributed under the terms and conditions of the Creative Commons Attribution license (http://creativecommons.org/licenses/by/4.0/). 